\title{
Functional analysis of human MLH1 mutations in Saccharomyces cerevisiae
}

Hideki Shimodaira et al.

Nature Genet. 19, 384-389 (1998).

Due to a typographical error, the genotypes of two yeast strains were reported incorrectly. The corrected genotypes are shown as follows:

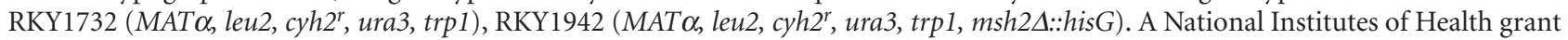
number was erroneously described as GM50006; it is, in fact, GM44704.

\section{Genomic imprinting is disrupted in interspecific Peromyscus hybrids}

Paul Vrana et al.

Nature Genet. 20, 362-365 (1998).

A typographical error occurred on page 362. The sentence should instead read " $P$. maniculatus and P. polionotus became evolutionarily separated approximately 100,000 years ago ${ }^{9}$, but it is not known when monogamy became fixed in the latter".

\section{Mutations in the gene encoding gap junction protein $\beta-3$ associated with autosomal dominant hearing impairment}

Jia-hi Xia et al.

Nature Genet. 20, 370-373 (1998).

One of the two GJB3 mutations we described lies at amino acid position 183. The mutation results in the substitution of a lysine residue for a glutamate residue, rather than a glutamine residue, as we originally proposed. We thank Andrew Griffith, of the US National Institutes of Health, for bringing this to our attention.

\section{Options available-from start to finish—for obtaining expression data by microarray}

David Bowtell

Nature Genet. 21, 25-32 (1999).

Table 3; High-density microarrays

Details of Affymetrix software are as follows.

GeneChip ${ }^{\circledR}$ EDMT, priced from \$2,500-\$3,250 per seat depending on geography, facilitates the mining of expression data contained in the GATC ${ }^{\mathrm{TM}}$ database created by GeneChip LIMS.

GeneChip ${ }^{\circledR}$ LIMS is a client/server software that facilitates the tracking of experimental and expression information in a relational database architecture. The server software is priced from $\$ 70,000-\$ 98,000$ and access licenses are priced from $\$ 2,500-\$ 3,250$ per seat depending on geography. 